\title{
CLINICOPATHOLOGICAL STUDY OF NASAL MASS- A TERTIARY CARE HOSPITAL BASED STUDY
}

\author{
Kamalini Bepari¹, Utkal Priyadarshi Mishra², Souvagini Acharya ${ }^{3}$, Sujit Kumar Brahma ${ }^{4}$
}

${ }^{1}$ Assistant Professor, Department of ENT, VIMSAR, Burla.

23rd Year Postgraduate Student, Department of ENT, VIMSAR, Burla.

${ }^{3}$ Associate Professor, Department of ENT, VIMSAR, Burla.

${ }^{4}$ Assistant Professor, Department of ENT, PRM Medical College, Baripada.

\section{ABSTRACT}

\section{BACKGROUND}

The nose is the most prominent feature of the face and often catches the attention of the onlookers whenever it is deformed or altered in shape. Frequently patients attend ENT clinic with complaints of nasal obstruction, nasal discharge, nasal bleeding, anosmia, etc. In many cases this may be due to a mass in the nasal cavity. The present study is undertaken with a view to evaluate the aetiology of various nasal masses, correlate histological findings with clinical manifestations and attempt has been made to diagnose the tumour early to assist in planning management.

\section{MATERIALS AND METHODS}

This is a prospective study carried out in Dept. of ENT, VIMSAR, Burla over a period of 2 years. Total 130 patients with nasal mass were included in the study. After a thorough clinical evaluation which includes detailed history, symptomatology, routine and special investigations, patients were subjected to diagnostic nasal endoscopy, imaging of nose and PNS. For confirmation of diagnosis incisional or excisional biopsy with histopathological examination is done.

\section{RESULTS}

Out of 130 cases with nasal mass, 94 cases (73\%) were non-neoplastic, 28 cases (21.53\%) were benign and only 8 cases (5.38\%) were malignant. Rhinosporidiosis was the most common nasal mass (34.61\%) followed by AC polyp. Among nasal malignancy, the commonest is squamous cell carcinoma of maxillary sinus (37.5\%). Nasal masses are more common in $2^{\text {nd }}$ decade of life but malignancy of nose/PNS was common in $4^{\text {th }}-6^{\text {th }}$ decade. Nasal masses were more common in males. Unilateral nasal obstruction was the presenting symptom in almost all cases.

\section{CONCLUSION}

Rhinosporidiosis, which was the most common nasal mass in our study is widely prevalent in western Odisha and is quite notorious for recurrence. As for the malignant condition of nose and PNS are concerned, early detection remains the key. It requires the combined effort of the surgeon, radiologist and pathologist for proper management. As most of these conditions have late presentations all the nasal masses should be examined thoroughly. However, health awareness among common people is of utmost importance for early diagnosis and management.

\section{KEYWORDS}

Nasal Mass, Clinicopathological, Rhinosporidiosis, AC Polyp, Angiofibroma.

HOW TO CITE THIS ARTICLE: Bepari K, Mishra UP, Acharya S, et al. Clinicopathological study of nasal mass- A tertiary care hospital based study. J. Evolution Med. Dent. Sci. 2017;6(38):3051-3055, DOI: 10.14260/Jemds/2017/658

\section{BACKGROUND}

The nose is the most prominent feature of the face and often catches the attention of the onlookers whenever it is deformed or altered in shape. Nose is not only important functionally but also anatomically and aesthetically as well. What is pleasing and what is beautiful is difficult to answer and depends upon the emotional reactions of the beholders.

Frequently patients attend ENT clinic with complaints of nasal obstruction, nasal discharge, nasal bleeding, anosmia, etc. In many cases this may be due to a mass in the nasal cavity. The mass may be an inflammatory swelling, a benign

Financial or Other, Competing Interest: None.

Submission 17-03-2017, Peer Review 01-04-2017,

Acceptance 06-05-2017, Published 11-05-2017.

Corresponding Author:

Dr. Utkal Priyadarshi Mishra

C/o - Jagannath Patjoshi,

At - Majhipali, Near Sibanand Ashram,

Burla, Sambalpur 768017,

Odisha.

E-mail: drutkal.mishra@gmail.com

DOI: $10.14260 /$ jemds $/ 2017 / 658$

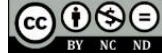

tumour or a malignant growth. Therefore, proper appreciation of the pathology is essential to guide the correct medical or surgical intervention.

Tumours in the nasal cavity and paranasal sinuses were recognised during the time of Hippocrates. Willis (1948) defined tumours as "an abnormal mass of tissue, growth of which exceeds and is uncoordinated with that of the normal tissues and persists in the same excessive manner after cessation of the stimuli which evoked the change."[1]

Because of the close relation of nose and paranasal sinuses to various important structures e.g. upper aerodigestive tract, orbit and skull base as well as cranial cavity, malignant diseases of nose and paranasal sinuses easily spread to these structures with devastating results, even before distant metastasis occurs. Their initial presentation may not be different from that of other common benign diseases. It has been recognised since long that malignant diseases of nose and paranasal sinuses can remain asymptomatic for quite a long period of time before giving rise to symptoms like any other malignant tumours. In one series the average duration between the initial symptoms and confirmation of diagnosis was 6 months. 
The present study is undertaken with a view to evaluate the aetiology, correlate histological findings with clinical manifestations and an attempt has been made to diagnose the tumour early to assist in planning management.

\section{MATERIALS AND METHODS}

This is a prospective study carried out in Dept. of ENT, VIMSAR, Burla. Total 130 patients with nasal mass irrespective of age and sex were included in the study. Patients with a definite mass in nose are admitted to the ENT ward for a thorough clinical study which includes detailed history, symptomatology, routine and special investigations and histopathological assessment of the lesion. The history includes occupational and socioeconomic status and personal habits of patients. After detailed nasal examination, diagnostic nasal endoscopy is done. X-ray PNS and CT-scan of nose, PNS and nasopharynx done in all cases. For confirmation of diagnosis incisional or excisional biopsy with histopathological examination is done. Patients are treated by surgery, radiotherapy, chemotherapy or pharmacotherapy. Patients were followed up on $15^{\text {th }}$ day, 3 months and 6 months postop. Ethical approval was obtained from VIREC (Institutional Ethical Committee). Statistical analysis done online by socscistatistics.com software.

\section{RESULTS}

Out of total number of 20,215 patients attending ENT Outpatient Department, 459 cases presented with nasal mass but only 130 cases $(0.64 \%)$ were followed up till 6 months.

Out of 130 cases with nasal mass, 94 cases $(73 \%)$ are non-neoplastic, 28 cases (21.53\%) were benign and only 8 cases $(5.38 \%)$ were malignant. This is in accordance with the study by Lewis et al (1972) which states that malignancy of nose and PNS are very rare.[2] Weimerf and Batsakis (1978) in their study found prevalence of malignancy of nose to be $1 \% \cdot{ }^{[3]}$

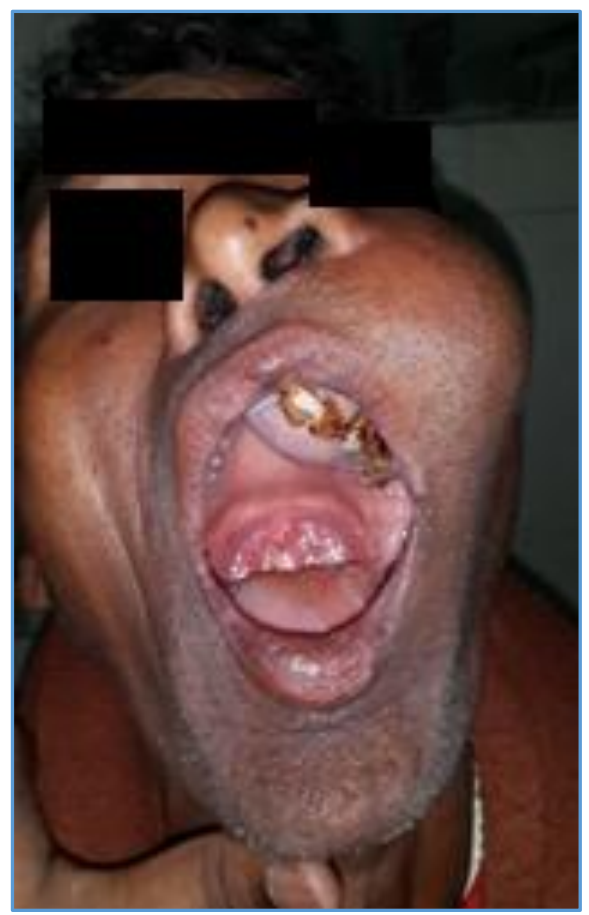

Figure 1. Ossifying Fibroma of Left Maxilla

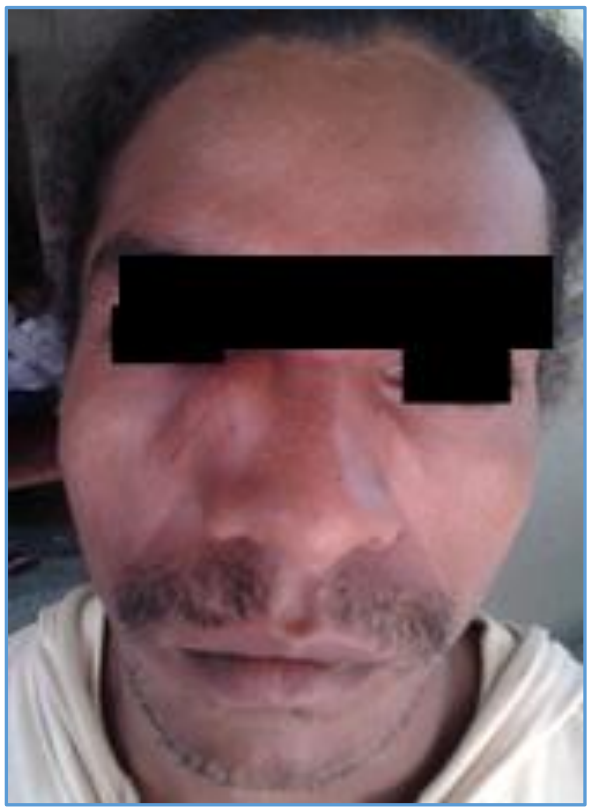

Figure 2. Pleomorphic Adenoma Involving Lateral Wall of Nose

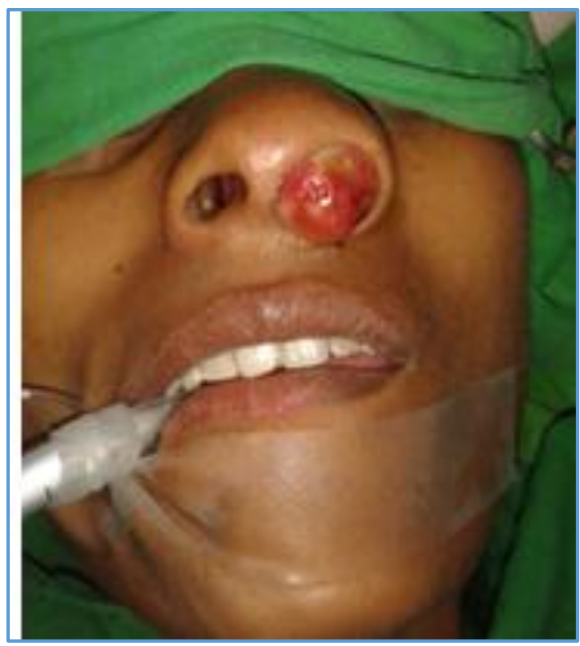

Figure 3. Juvenile Nasopharyngeal Angiofibroma of Left Nasal Cavity in a 14-year-old Male

In our study, we observed that among 130 patients with nasal mass, rhinosporidiosis was the most common nasal mass (34.61\%) followed by AC polyp (16.92\%), ethmoidal polyp (13.84\%), haemangioma (7.7\%), malignant conditions of nose and PNS (6.15\%). These findings are slightly different from previous studies in which AC polyp was the commonest nasal mass. ${ }^{[4]}$ Rhinosporidiosis is most common in our study. We attribute this finding to rampant pond bathing habit of patients of Western Odisha. Considering the malignant conditions of nose and PNS, the commonest is Squamous cell carcinoma of maxillary sinus $(37.5 \%)$ followed by Squamous cell carcinoma of nose $(25 \%)$ and Adenocarcinoma of Maxillary sinus (12.5\%). These findings are comparable with reports of Cheesman et al and Bahadur et al who also found Squamous cell carcinoma to be the commonest malignant condition of nose. ${ }^{[5],[6]}$ 


\begin{tabular}{|c|c|c|c|c|c|}
\hline \multirow{2}{*}{$\begin{array}{c}\text { Sl. } \\
\text { No. }\end{array}$} & \multirow{2}{*}{ Types of Mass } & $\begin{array}{c}\text { Male } \\
\text { Cases }\end{array}$ & \% & $\begin{array}{c}\text { No. of } \\
\text { Cases }\end{array}$ & \% \\
\cline { 3 - 6 } & \multicolumn{5}{|c|}{ Nooplastic } \\
\hline 1 & Rhinosporidiosis & 32 & 71 & 13 & 9 \\
\hline 2 & Antrochoanal Polyp & 12 & 54.5 & 10 & 45.5 \\
\hline 3 & Ethmoidal Polyp & 10 & 55.5 & 8 & 45.5 \\
\hline 4 & Cyst & 3 & 60 & 2 & 40 \\
\hline 5 & Fungal Granuloma & 3 & 75 & 1 & 25 \\
\hline \multicolumn{5}{|c|}{ Benign Tumours } \\
\hline 6 & Haemangioma & 4 & 40 & 6 & 60 \\
\hline 7 & Squamous Cell Papilloma & 3 & 50 & 3 & 50 \\
\hline 8 & Angiofibroma & 3 & 100 & 0 & 0 \\
\hline 9 & Inverted Papilloma & 3 & 100 & 0 & 0 \\
\hline 10 & Neurofibroma & 1 & 100 & 0 & 0 \\
\hline 11 & $\begin{array}{c}\text { Ossifying Fibroma of } \\
\text { Maxilla }\end{array}$ & 0 & 0 & 1 & 100 \\
\hline 12 & Pleomorphic Adenoma & 1 & 100 & 0 & 0 \\
\hline 13 & \multicolumn{6}{|c|}{ Fibroma Malignant Tumours } \\
\hline \multicolumn{6}{|c|}{ Table 1. Sex Incidence Of Various Nasal Mass } \\
\hline 14 & Sq. Cell Ca. Maxilla & 2 & 66.66 & 1 & 33.33 \\
\hline 15 & Sq. Cell Ca. Nose & 2 & 100 & 0 & 0 \\
\hline 16 & Sq. Cell Ca. Ethmoid & 0 & 0 & 1 & 100 \\
\hline 17 & $\begin{array}{c}\text { Adenoid cystic Ca. } \\
\text { Maxilla }\end{array}$ & 1 & 100 & 0 & 0 \\
\hline 18 & $\begin{array}{c}\text { Adenocarcinoma } \\
\text { Maxillary Sinus }\end{array}$ & 1 & 100 & 0 & 0 \\
\hline & 2 & 66 & 1 & 33 \\
\hline
\end{tabular}

On comparing the age incidence of various nasal masses, we found Rhinosporidiosis and Antrochoanal polyp were observed mostly in $2^{\text {nd }}$ decade of life (33.33\%). This finding is in accordance with the findings of Allen and Dave et al. Ethmoidal polyp is a disease of adults and incidence is maximum between 30-40 years of age (Lee, 1984), which coincides with our study.[7] We also found maximum incidence of AC polyp in 31-40 years group (33.33\%). In the present study, all the cases of malignancy of nose are above 40 years of age with peak incidence at 51-60 years (65\%). Lederman et al also found sharp increase in the incidence of malignancy in nose after the $4^{\text {th }}$ decade of life. Finally, 3 cases of nasopharyngeal angiofibroma were seen between 11-20 years of age.

On comparing the sex incidence, the incidence of nasal mass was noted to be higher in males (63.84\%). Rhinosporidiosis, AC polyp, ethmoidal polyp are more common in males. All the cases of nasopharyngeal angiofibroma were male. This coincides with the findings of Figi (1940) and Das (1970).

\begin{tabular}{|c|c|c|c|c|c|c|c|c|c|c|}
\hline $\begin{array}{c}\text { Sl. } \\
\text { No. }\end{array}$ & $\begin{array}{c}\text { Benign } \\
\text { Tumours }\end{array}$ & $\begin{array}{c}\text { Nasal } \\
\text { Obstruction }\end{array}$ & $\begin{array}{c}\text { Nasal } \\
\text { Discharge }\end{array}$ & Epistaxis & Anosmia & Toothache & Facial Swelling & Facial Pain & Trismus & Proptosis \\
\hline 1 & Haemangioma & 6 & 4 & 10 & - & - & - & 2 & - & - \\
\hline 2 & $\begin{array}{l}\text { Squamous Cell } \\
\text { Papilloma }\end{array}$ & 2 & 2 & 1 & - & - & - & - & - & - \\
\hline 3 & Angiofibroma & 3 & 2 & 2 & & & 2 & 1 & - & - \\
\hline 4 & Fibroma & 3 & 3 & 3 & 1 & - & - & - & - & - \\
\hline 5 & Inverted Papilloma & 3 & 3 & - & - & - & - & - & - & - \\
\hline 6 & \begin{tabular}{|c|}
$\begin{array}{c}\text { Ossifying Fibroma } \\
\text { of maxilla }\end{array}$ \\
\end{tabular} & 1 & 1 & - & - & - & 1 & - & - & - \\
\hline 7 & $\begin{array}{l}\text { Pleomorphic } \\
\text { Adenoma }\end{array}$ & 1 & 1 & - & - & - & 1 & - & - & - \\
\hline 8 & Sq Cell Ca. Maxilla & 3 & 3 & 3 & 1 & 1 & 3 & 1 & 1 & - \\
\hline 9 & Sq. cell Ca. nose & 2 & 2 & 1 & 2 & - & 1 & 1 & - & - \\
\hline 10 & Sq. Cell Ca. Ethmoid & 1 & 1 & 1 & - & - & 1 & 1 & - & 1 \\
\hline 11 & \begin{tabular}{|c|}
$\begin{array}{c}\text { Adenoid cystic Ca. } \\
\text { Maxilla }\end{array}$ \\
\end{tabular} & 1 & 1 & 1 & - & 1 & 1 & 1 & - & - \\
\hline 12 & $\begin{array}{l}\text { Adenocarcinoma } \\
\text { maxillary sinus }\end{array}$ & 1 & 1 & 1 & - & 1 & 1 & 1 & - & - \\
\hline \multicolumn{11}{|c|}{ Table 2. Symptomatology of Neoplastic Nasal Mass } \\
\hline
\end{tabular}

On assessing the symptomatology, the commonest symptom in patients with nasal mass was Unilateral/Bilateral nasal obstruction in both neoplastic and non-neoplastic nasal mass. Commonest symptom in patients with rhinosporidiosis was epistaxis (84.3\%). Headache was found in $66.6 \%$ cases of ethmoidal polyp and $45 \%$ cases of antrochoanal polyp. Sneezing was observed in $66.6 \%$ cases of ethmoidal polyp and $20 \%$ cases of antrochoanal polyp. Mucopurulent nasal discharge was seen in $54.5 \%$ cases of antrochoanal polyp. Drake Lee et al in their report stated that the nasal discharge may be purulent, mucopurulent or mucoid depending upon the complicating diseases of sinuses. ${ }^{[8]}$ In this observation, $55.5 \%$ cases of rhinosporidiosis had attachment in lateral wall and $15.5 \%$ cases had attachment to floor. Das (1974) found attachment of rhinosporidiosis to lateral wall in $22.5 \%$ cases.

In this study, epistaxis was found in $70 \%$ cases of malignancy. Local pain was observed in cases of malignancy and inverted papilloma with secondary infection. Fullness of cheek was found in $58.3 \%$ cases of malignant tumours. Mass in hard palate was present in $50 \%$ of cases. Only one case presented with lymphadenopathy and cranial nerve palsy.

On radiological assessment, it was observed bone erosion occurred only in cases of malignancy (70\%) and fungal granuloma. Haziness of sinuses was found in 19 cases of antrochoanal polyp and 16 cases of ethmoidal polyp. 
Analysis of blood revealed $\mathrm{Hb}$ less than $10 \mathrm{~g} \%$ in total 38 (29.3\%) cases among which $66.66 \%$ were malignancy and 2 were nasopharyngeal fibroma. This may be due to chronic blood loss from repeated epistaxis. In a study of differential count, $54.5 \%$ of cases of ethmoidal polyp had eosinophilia, which signifies that this condition has a strong relation with allergy. No significant rise in ESR was seen in any of these cases.

\section{Histopathological Study \\ Rhinosporidiosis}

This consists of very vascular, fibromyxomatous connective tissue in which the various stages of development of sporangia are seen in stroma in different sections. There are plenty of lymphocytes and plasma cells, polymorphonuclear cells and eosinophils are also present.

\section{Nasal Polyp}

The mucosa is oedematous and hypertrophied. It is covered by ciliated columnar epithelium. The epithelium had undergone squamous metaplasia at places. At some sites, there was oedema and lamina propria was greatly distended. Accumulation of plasma cells, lymphocytes, eosinophils and varied number of polymorphonuclear cells were seen. Fibroblasts and histiocytes were also present. Stroma was fibrillar with large spaces filled with intercellular fluid. Glands were few and distended. There were perilymphatic and perivenular inflammatory infiltrations.

\section{Fungal Granuloma}

The fungal hyphae are identified by special stains (methenamine silver). They are seen as separate hyphae and dichotomous branching at an angle of $45^{\circ}$.

\section{Malignancy}

In the present series among 8 cases of malignancy of nose and PNS, 6 were squamous cell CA. 1 adenocystic CA. and 1 was adenocarcinoma of maxilla.

\section{Squamous Cell Carcinoma}

This consists of down growth and masses of enlarged epithelial cells which show marked variation and irregularity in their size. Many atypical mitoses are seen. Concentric nests of keratinised cells forming epithelial pearls and prickle cells are present. Nuclei are hyperchromatic and basement membrane were invaded by the tumour cells.

\section{Adenoid Cystic Carcinoma}

The tumour is composed of rather uniform basaloid cells. Tumour cells were arranged in strands and clumps surrounding acellular spaces that contain a hyaline material imparting a "Swiss cheese appearance".

\section{Papilloma}

Out of 9 cases of papilloma studied in this series, 6 were squamous papillomas and 3 were inverted papillomas. Papilloma on HPE showed numerous prominent invagination of epithelium into the stroma. Overlying epithelium is predominantly transitional in type with cuboidal, columnar or squamous types in different areas. Dyskeratosis and vacuolation in individual cells is commonly seen in the epithelial layer giving rise to pseudoglands. The basement membrane is intact, stroma consists of loose vascular connective tissue with occasional plasma cells and lymphocyte infiltration.

\section{Haemangioma}

Histologically it shows mantling of mesenchymal cells of blood vessels. The cells are highly undifferentiated and lie in association with considerable amount of connective tissue.

\section{Nasopharyngeal Angiofibroma}

The section shows dense fibrous tissue with tremendous vascularity. The vessels are of various calibre and irregular in shape. The walls of the vessels at places consists only of endothelial cells. The stroma consists of matrix of collagenous fibrils interwoven in an irregular manner.

\section{CONCLUSION}

130 patients of nasal mass attending ENT OPD, VIMSAR, Burla within 2 years period were taken for study which comprises $0.64 \%$ of total patients of that period. Rhinosporidiosis was found to be the most common lesion among them followed by AC Polyp and Ethmoidal polyp. Among benign nasal masses commonest was haemangioma constituting $7.71 \%$ of cases followed by Squamous cell papilloma, inverted papilloma. Angiofibroma was the least common among benign nasal masses. Out of all malignant nasal masses, squamous cell carcinoma was most common. Nasal masses are more common in $2^{\text {nd }}$ decade of life followed by $3^{\text {rd }}$ decade, but malignancy of nose/PNS was common in $4^{\text {th }}-6^{\text {th }}$ decade. In our study, nasal masses are more common in males. Rhinosporidiosis was commonly found in rural population and cultivators. Unilateral nasal obstruction was the presenting symptom in almost all nasal masses except ethmoidal polyp where obstruction is bilateral. Epistaxis was seen in $45 \%$ cases of nasal mass comprising of rhinosporidiosis, haemangioma, angiofibroma and malignancy. It was observed that most nasal masses take origin from lateral wall of nose. Histopathologically of all cases of malignant conditions of nose/PNS, 75\% cases were Squamous cell carcinoma, Adenoid cystic CA and Adenocarcinoma each being $12 \%$.

Rhinosporidiosis, which was the most common nasal mass in our study is widely prevalent in western Odisha and is quite notorious for recurrence. As for the malignant condition of nose and PNS are concerned, early detection remains the key. It requires the combined effort of the surgeon, radiologist and pathologist for proper management. As most of these conditions have late presentations all the nasal masses should be examined thoroughly. However, health awareness among common people is of utmost importance for early diagnosis and management.

\section{REFERENCES}

[1] Ramzi CS, Vinay K, Tucker C, et al. Pathologic basis of disease. $8^{\text {th }}$ edn. Chapter neoplasia. Philadelphia: Elsevier publications 2010:259-330.

[2] Lewis JS, Castro EB. Cancer of the nasal cavity and paranasal sinuses. J Laryngol otol 1972;86(3):255-62. 
[3] Nishiyama RH, Batsakis JG, Weaver DK. Nasopharyngeal carcinomas in children. Arch Surg 1967;94(2):214-7.

[4] Lathi A, Syed MMA, Kalakoti P, et al. Clinicopathological profile of sinonasal masses: a study from a tertiary care hospital of India. Acta Otorhinolaryngol Ital 2011;31(6):372-7.

[5] Bahadur S, Tandon DA, Mahapatra AK, et al. Craniofacial resection for lesions involving anterior base of skull. Indian J Otolaryngol Head Neck Surg 1996;48(4):295-300.
[6] Cheesman AD, Lund VJ, Howard DJ. Craniofacial resection for tumors of the nasal cavity and paranasal sinuses. Head Neck Surg 1986;8(6):429-35.

[7] Allen WM, Schwartz DL, Rana V, et al. Long term radiotherapy outcomes for nasal cavity and septal cancers. Int J Radiat Oncol Biol Phys 2008;71(2): 401-6.

[8] Drake-Lee AB. Nasal polyps. In: Kerr AG, Mackay AS, Bull TR, (eds). Scott-Brown's otolaryngology. Chapter 6. Vol: 4. Rhinology, Oxford: Butterworth-Heinemann 1997. 